Gut, 1982, 23, 164-168

Case report

\title{
Rectal malignant lymphoma in chronic ulcerative colitis
}

\author{
D BARTOLO, J R GOEPEL, AND M A PARSONS \\ From the Department of Surgery, Royal Hallamshire Hospital, Sheffield, and the Department of Pathology, \\ Sheffield University Medical School, Sheffield
}

SUMMARY Carcinoma of the colon as a complication of ulcerative colitis is relatively common, whereas malignant lymphoma is apparently rare; there are approximately 20 recorded cases. We report a case of follicular lymphoma of the rectum in a 73 year old woman with a 21 year history of ulcerative colitis. In view of the possible immune basis of ulcerative colitis, it is important to report and accurately classify cases of lymphoma arising in association with it.

Carcinoma of the colon as a complication of ulcerative colitis is relatively common, whereas malignant lymphoma is apparently rare. Primary malignant lymphoma of the large intestine is itself rare. ${ }^{12}$ There are now approximately 20 recorded cases of large intestinal malignant lymphoma arising in patients with long-standing ulcerative colitis ${ }^{1-16}$ and one case of malignant lymphoma arising in the terminal ileum of a patient with a ileostomy after colectomy for ulcerative colitis. ${ }^{17}$ We report a follicular lymphoma of the rectum arising in a 73 year old woman with a 21 year history of ulcerative colitis, and include immunohistochemical and ultrastructural findings to support the diagnosis.

\section{Methods}

The colon and rectum were opened before fixation in $10 \%$ formol saline. Paraffin sections were prepared, and stained by haematoxylin and eosin, periodic acid-Schiff after diastase digestion, Gömöri's reticulin method, and methyl-green-pyronin. Material for electron microscopy was selected from the tumour and fixed in $4 \%$ glutaraldehyde, postfixed in osmium tetroxide, and the sections stained by uranyl acetate and lead citrate.

Paraffin-embedded tumour material was used for immunohistochemical investigation. A controlled trypsin-immunoperoxidase PAP technique modified from the PAP method of Mason et al..$^{18-20}$ was used to determine the

Received for publication 8 July 1981 distribution of heavy chains of immunoglobulins (Ig) G, A, M, D, and E, kappa and lambda light chains, lysozyme, and albumin. Trypsin (type II crude pancreatic) was purchased from SIGMA Chemical Company, rabbit anti-human antisera, rabbit PAP, and normal rabbit serum from DAKO, goat anti-rabbit immunoglobulins from Nordic Immunological Laboratories, goat anti-human antisera from Kallerstat Laboratories, and 3,3' diaminobenzidine from BDH Chemicals.

\section{Case report}

A 73 year old Caucasian woman presented in December 1979 with a 21 year history of ulcerative colitis. Rectal biopsy and barium enema in 1974 had confirmed the diagnosis and shown narrowing and shortening of the whole colon. In 1978 digital examination suggested thickening of the rectal wall, but a biopsy and barium enema showed ulcerative colitis only (Fig. 1). By December 1979 her complaint was a constant feeling of pressure in the rectum, and rectal examination revealed a large smooth annular mass which was biopsied. Histologically, there was a small area of monomorphic lymphoid cells in the submucosa, and a diagnosis of malignant lymphoma was made. Superficial lymph nodes and radiograph of the chest were normal, and laboratory investigations showed a haemoglobin of $12.5 \mathrm{~g} / \mathrm{dl}$, white cell count of $4.8 \times 10^{9} / 1$ with normal differential, and erythrocyte sedimentation rate of $46 \mathrm{~mm}$ in one hour. Panprotocolectomy was performed and no abnormality of liver, spleen, or abdominal lymph 


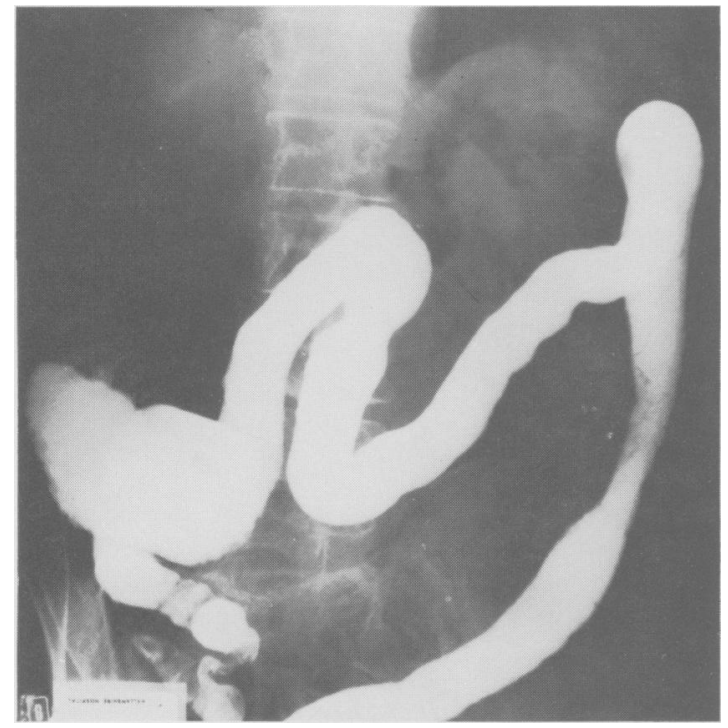

Fig. 1 Barium enema in 1978 showing long-standing ulcerative colitis.

nodes was seen. Subsequently, isotope scans of liver and spleen and lymphangiography have also failed to show any evidence of disease. No further treatment has been given, and the patient shows no evidence of lymphoma at 12 months' follow-up.

\section{GROSS PATHOLOGY}

The specimen showed an $8 \mathrm{~cm}$ annular mass infiltrating the mucosa and muscle of the rectal wall and a smaller mass $4 \mathrm{~cm}$ proximally. The cut surface showed a uniform pale appearance with very little mucosal ulceration (Fig. 2). The remainder of the bowel showed typical features of the long-standing ulcerative colitis.

\section{LIGHT MICROSCOPY}

The tumour was composed of lymphoid cells: many cells showed a small irregular or cleaved nucleus, though about $40 \%$ of cells were larger with a rounded or irregular nucleus (Fig. 3). In addition, plasma cells and histiocytes were present within and around the tumour mass. The reticulin stain demonstrated evidence of follicle formation. These features enable the tumour to be classified as a follicular lymphoma of mixed small and large follicle cells (National Lymphoma Investigation Classification $\left.{ }^{21}\right)$. Local lymph nodes showed normal reactive changes only. The colonic and rectal mucosa showed features of long-standing, quiescent ulcerative colitis (Fig. 4).

\section{ELECTRON MICROSCOPY}

The tumour cells showed irregular and indented nuclear outlines with the chromatin in small clumps centrally and around the margin. The cytoplasm contained few organelles but numerous ribosomes; a few cells contained short lengths of rough endoplasmic reticulum. Golgi zones and welldeveloped stacks of this reticulum were not a feature. Mature histiocytes and plasma cells were identifiable among the tumour cells.

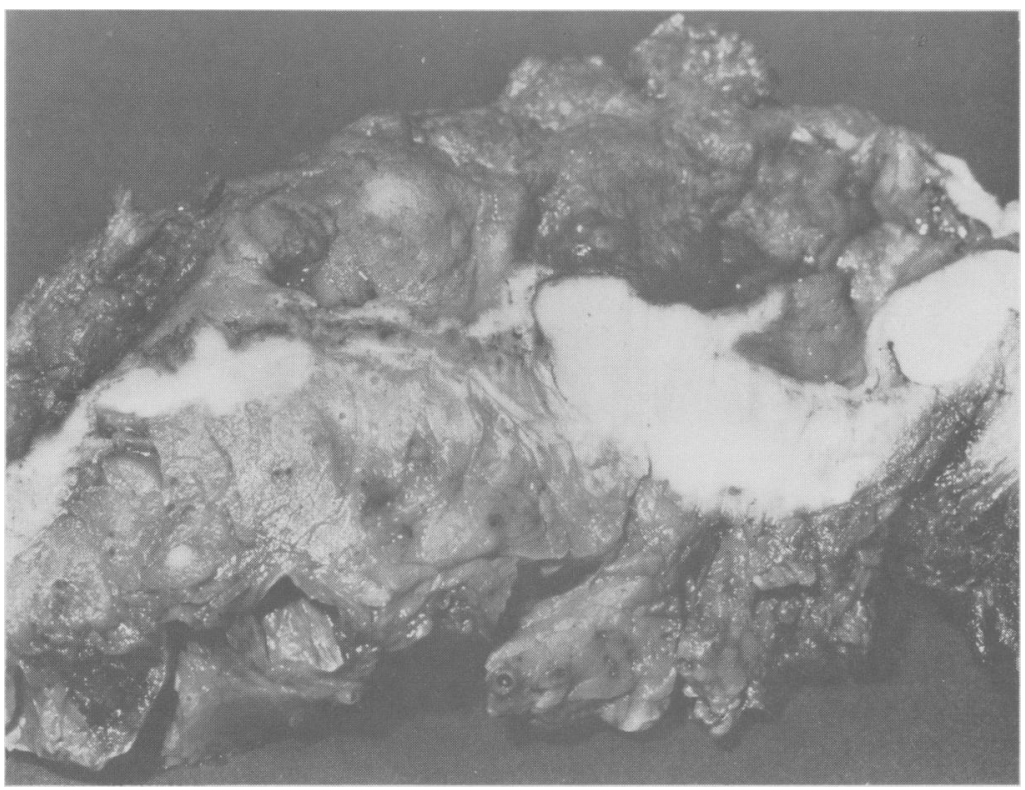

Fig. 2 Operation specimen after fixation. Longitudinal section of rectum showing pale tumour infiltrating the wall; two foci are present. 


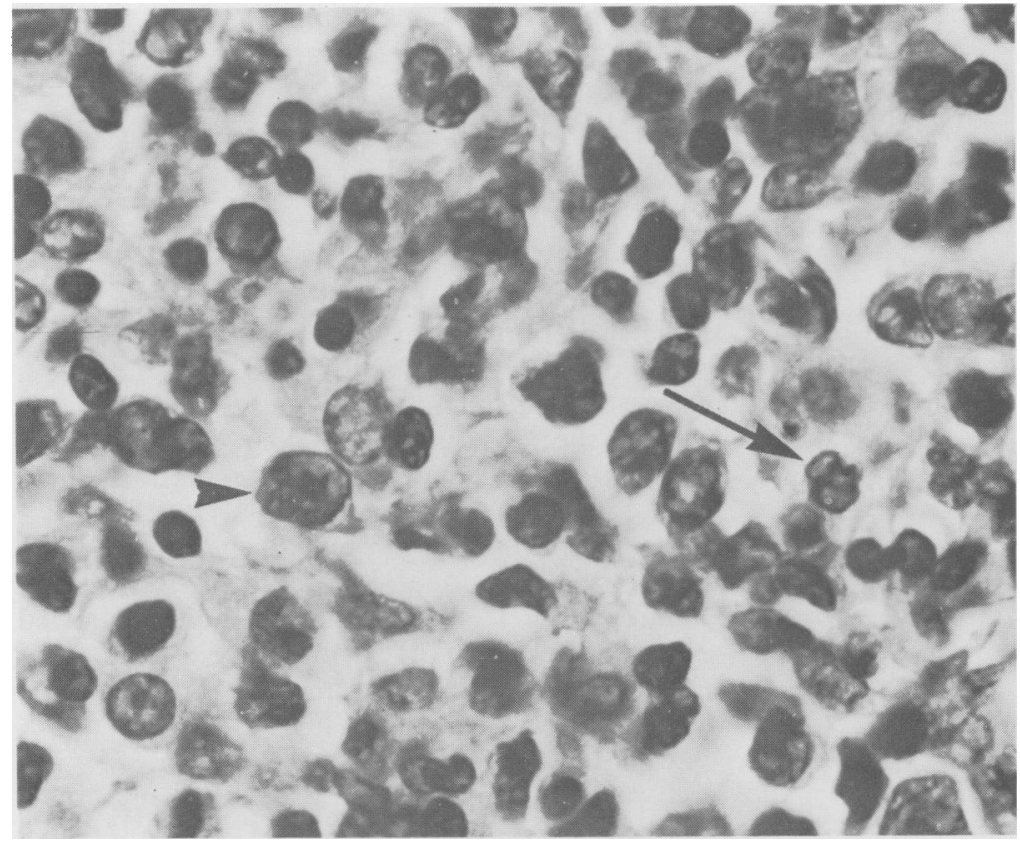

Fig. 3 Detail of the lymphoma showing small cells with an irregular outline (arrow) and larger cells (arrowhead).

$H$ and $E, \times 1000$

(original magnification).

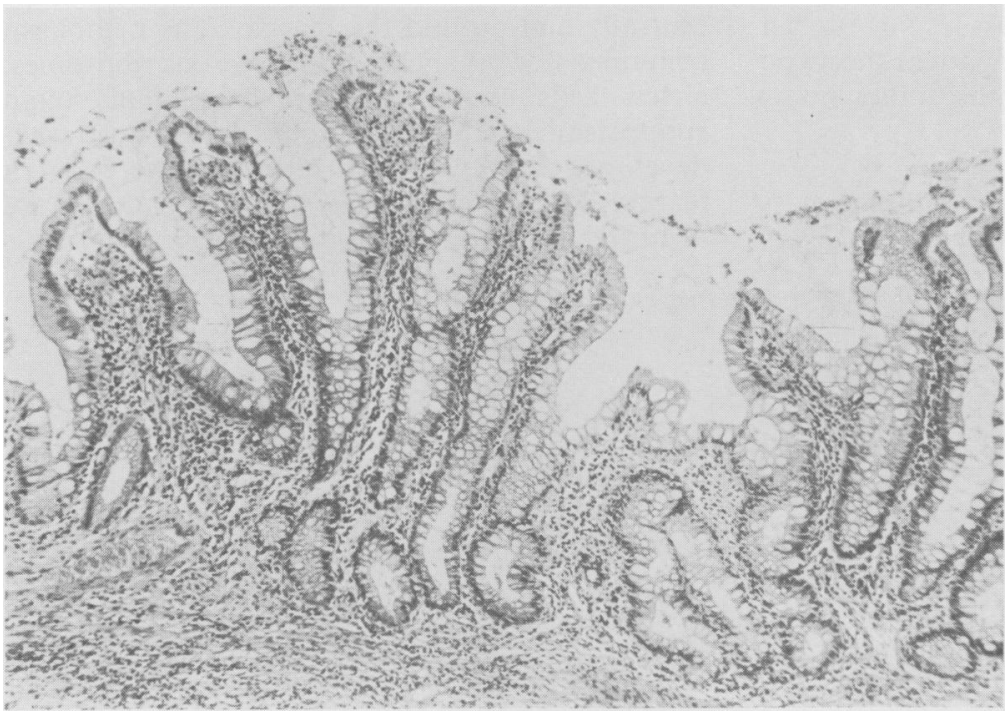

Fig. 4 Rectal mucosa showing the marked glandular distortion of quiescent long-standing ulcerative colitis.

$H$ and $E, \times 100$

(original magnification).

\section{IMMUNOHISTOCHEMISTRY}

There was no evidence that the tumour contained immunoglobulin heavy or light chains, or lysozyme. Plasma cells containing IgG, IgM, IgA, kappa, or lambda light chains, and histiocytes containing lysozyme were present within the tumour. The adjacent mucosa contained plasma cells staining predominantly for IgA and kappa or lambda light chains. All negative control sections and endogenous negative control cells were negative.

\section{Discussion}

Malignant lymphoma of the large intestine in association with chronic ulcerative colitis is very rare, whereas adenocarcinoma is an accepted risk. ${ }^{22}$ There are only about 20 recorded cases of 
lymphoma, though an accurate estimate is difficult because previously reported cases are included among new series 910 and this distinction is lost in later reviews. ${ }^{15} 16$

Since the first two cases of ulcerative colitis associated with malignant lymphoma appeared in $1928^{3}$ case reports have been complicated by frequent changes in the classification of lymphomas, though in about half the cases detailed classification was not attempted. ${ }^{15}$ About four cases of Hodgkin's disease are recorded, but this diagnosis must now be in doubt in view of recent series of intestinal lymphoma. ${ }^{1723}$ Henry and Farrer-Brown ${ }^{23}$ reviewed 125 cases of intestinal lymphoma and reclassified all five cases of Hodgkin's disease as plasma cell tumour. Contrary to this, Isaacson and Wright ${ }^{24}$ published a series of 18 cases of malignant histiocytosis associated with malabsorption, and suggested that some of Henry and Farrer-Brown's cases were, in fact, malignant histiocytosis with reactive plasma cells. In this context, it is disquieting that a recent report of histiocytic lymphoma in chronic ulcerative colitis ${ }^{16}$ gives no indication whether the authors mean malignant histiocytosis or 'histiocytic' in the Rappaport sense. ${ }^{25}$ Assuming they mean the latter, it is likely that all the lymphomas associated with colitis are of B-lymphocyte lineage.

Our case fulfils Dawson's criteria of a primary malignant lymphoma of the intestinal tract. ${ }^{26}$ Detailed study of the tumour shows a follicular lymphoma with a reactive infiltrate of plasma cells and histiocytes. It is thus also of B-lymphocyte origin.

In view of the small number of reported cases, it is questionable if malignant lymphoma is causally related to ulcerative colitis. However, if all the lymphomas are of the same histogenesis then a common aetiology is possible. Marked lymphoid follicular hyperplasia, a B-lymphocyte phenomenon, is common in chronic ulcerative colitis ${ }^{5}$ and may be related to the development of malignant lymphoma.

It is important to be aware of the possibility of malignant lymphoma in ulcerative colitis in order to evaluate correctly any lymphoid infiltrate seen in a biopsy.

We thank Mr C H Talbot for permission to publish details of this case and for his helpful comments; also Mrs R M Raine for typing the manuscript.

\section{References}

${ }^{1}$ Cornes JS, Smith JC, Southwood WF. Lymphosarcoma in chronic ulcerative colitis with report of two cases. Br J Surg 1961; 49:50-3.
${ }^{2}$ Warren S, Lulenski CR. Primary solitary lymphoid tumours of the gastrointestinal tract. Ann Surg 1942; 115:1-12.

${ }^{3}$ Bargen JA. Chronic ulcerative colitis associated with malignant disease. Arch Surg 1928; 17:561-76.

${ }^{4}$ Cattell RB, Boehme EJ. The importance of malignant degeneration as a complication of chronic ulcerative colitis. Gastroenterology 1947; 8:695-710.

sWarren KW. Malignant lymphoma of the duodenum, small intestine and colon. Surg Clin North Am 1959; 39:725-35.

${ }^{6}$ Delannoy E, Buffin RP. Réticulosarcome sur rectocolite hémorragique (colite ulcérative). Presse Med 1962; 70:1006-7.

'Sataline LR, Mobley EM, Kirkham W. Ulcerative colitis complicated by colonic lymphoma. Gastroenterology 1963; 44:342-7.

${ }^{8}$ Walker FC, Weaver JP. Lymphosarcoma in ulcerative colitis. Br J Surg 1964; 51:475-7.

${ }^{9}$ Wychulis AR, Beahrs OH, Woolner LB. Malignant lymphoma of the colon. A study of 69 cases. Arch Surg 1966; 93:215-25.

10Nugent FW, Zuberi S, Bulan MB, Legg MA. Colonic lymphoma in ulcerative colitis: report of four cases. Lahey Clin Found Bull 1972; 21:104-11.

"Parikh NK, Shah PM, Patel SM, Chandra DD. Colonic lymphoma in ulcerative colitis (a case report). $J$ Assoc Physns India 1973; 21:713-6.

${ }^{12}$ Renton P, Blackshaw AJ. Colonic lymphoma complicating ulcerative colitis. Br J Surg 1976; 63:542-5.

${ }^{13 V i e t a}$ JO, Delgado GE. Chronic ulcerative colitis complicated by colonic lymphoma: report of a case. Dis Colon Rectum 1976; 19:56-62.

${ }_{14}$ Wagonfield JB, Platz CE, Fishman FL, Sibley RK, Kirsner JB. Multicentric colonic lymphoma complicating ulcerative colitis. Am J Dig Dis 1977; 22:502-8.

${ }^{15}$ Emanuel JCM, Isbister WH. Chronic mucosal ulcerative colitis with malignant lymphoma: report of a case. Aust NZ J Surg 1979; 49:95-8.

${ }^{16}$ Bashiti HO, Kraus KT. Histiocytic lymphoma in chronic ulcerative colitis. Cancer 1980; 46:1695-700.

${ }^{17}$ Lewin KJ, Ranchod M, Dorfman RF. Lymphoma of the gastrointestinal tract. Cancer 1978; 42:693-707.

${ }^{18}$ Mason TE, Phifer RF, Spicer SS, Swallow RA, Dreskin RB. An immunoglobulin-enzyme bridge method for localizing tissue antigens. J Histochem Cytochem 1969; 17:563-9.

${ }^{19}$ Curran RC, Gregory J. The unmasking of antigens in paraffin sections of tissue by trypsin. Experientia 1977; 33:1400-1.

${ }^{20}$ Mepham BL, Frater W, Mitchell BS. The use of proteolytic enzymes to improve immunoglobulin staining by the PAP technique. Histochem $J$ 1979; 11:345-58.

${ }^{2}$ 'Bennett MH, Farrer-Brown G, Henry K, Jelliffe AM. Classification of non-Hodgkin's lymphomas. Lancet 1974; 2:405-6.

${ }^{22}$ Edwards FC, Truelove SG. The course and prognosis of ulcerative colitis. Gut 1964; 5:1-22.

${ }^{23}$ Henry K, Farrer-Brown G. Primary lymphomas of the gastrointestinal tract. I Plasma cell tumours. Histopathology 1977; 1:53-76. 
${ }^{24}$ Isaacson $\mathrm{P}$, Wright D H. Intestinal lymphoma associated with malabsorption. Lancet 1978; 1:67-70.

${ }^{25}$ Rappaport H. Tumors of the hematopoietic system. In: Atlas of tumor pathology. Sect 111, Fasc 8, Washington DC: Armed Forces Inst Pathol, 1966: 97-101.
${ }^{26}$ Dawson IMP, Comes JS, Morson BC. Primary malignant lymphoma of the intestinal tract. Report of 37 cases with a study of factors influencing prognosis. Br J Surg 1961; 49:80-9. 